\title{
Comments on "The role of percutaneous neurolysis in lumbar disc herniation: systematic review and meta-analysis"
}

\section{Min Cheol Chang}

Department of Rehabilitation Medicine, College of Medicine, Yeungnam University, Daegu, Korea

Received September 9, 2021, Revised September 24, 2021, Accepted September 24, 2021

Handling Editor: Kyung Hoon Kim

Correspondence

Min Cheol Chang

Department of Physical Medicine and Rehabilitation, College of Medicine, Yeungnam University, 170 Hyeonchung-ro, Nam-gu, Daegu 42415, Korea Tel: +82-53-620-4682, Fax: +0504-231-8694, E-mail: wheel633@gmail.com

\section{TO THE EDITOR}

I read the recently published article, "The role of percutaneous neurolysis in lumbar disc herniation: systematic review and meta-analysis" by Manchikanti et al. [1], with great interest. They performed a meta-analysis to evaluate the effectiveness of percutaneous epidural neurolysis or adhesiolysis in the management of chronic lumbar radiculopathy due to disc herniation by including 6 previous studies (1 randomized controlled trial and 5 retrospective single-arm studies) [2-7]. The standard mean differences in the change in pain and functional status after percutaneous epidural neurolysis or adhesiolysis ranged between -2 and -10 , indicating high therapeutic effectiveness. Moreover, Manchikanti et al. concluded that the level of evidence for the use of percutaneous epidural neurolysis or adhesiolysis in the management of recalcitrant disc herniation or lumbar radiculopathy is "II." However, I have some concerns regarding this study.

First, the authors have mentioned that they included studies that recruited patients with chronic disc herniation. The International Association for the Study of Pain has defined chronic pain as discomfort lasting longer than 3 months, and even clinicians usually consider pain as chronic if it lasts for 3 months or more [8]. However, of the 6 included studies in the meta-analysis, only 2 studies $[3,4]$ included patients with chronic lumbar radiculopathy (persistent pain for more than 3 months). The other 4 studies $[2,5-7]$ included even those patients whose pain did not persist for over 3 months, or they did not include "chronic pain" in the inclusion criteria.

Second, 2 studies $[3,7]$ included in the meta-analysis not only recruited patients with disc herniation, but also those with radicular pain induced by spinal stenosis. Because these 2 studies did not perform the sub-group analysis according to the disease types, the measured outcomes in patients with disc herniation and those with spinal stenosis were analyzed together. However, the study by Manchikanti et al. mentions that the inclusion criteria of these studies only included patients with chronic disc herniation. Furthermore, Manchikanti et al. have written the title and contents of the conclusion section indicating that these studies evaluated the effectiveness of the procedure only in patients with disc herniation. For accurate evaluation, the authors should have excluded the studies that included patients with spinal stenosis. (a) This is an open-access article distributed under the terms of the Creative Commons Attribution Non-Commercial License (http://creativecommons.org/licenses/by-nc/4.0/), which permits unrestricted non-commercial use, distribution, and reproduction in any medium, provided the original work is properly cited.

(c) The Korean Pain Society, 2022
Author contributions: Min Cheol Chang: Writing/manuscript preparation. 
In my opinion, a clarification of the aforementioned concerns is necessary in order to provide accurate information to the readers and increase the reliability of the meta-analysis.

\section{CONFLICT OF INTEREST}

No potential conflict of interest relevant to this article was reported.

\section{FUNDING}

No funding to declare.

\section{ORCID}

Min Cheol Chang, https://orcid.org/0000-0002-7629-7213

\section{REFERENCES}

1. Manchikanti L, Knezevic E, Knezevic NN, Sanapati MR, Kaye AD, Thota $S$, et al. The role of percutaneous neurolysis in lumbar disc herniation: systematic review and metaanalysis. Korean J Pain 2021; 34: 346-68.
2. Cho PG, Ji GY, Yoon YS, Shin DA. Clinical effectiveness of percutaneous epidural neuroplasty according to the type of single-level lumbar disc herniation: a 12-month follow-up study. J Korean Neurosurg Soc 2019; 62: 681-90.

3. Choi EJ, Yoo YJ, Lee PB, Kim YC, Lee SC, Moon JY. A retrospective study to evaluate the effect of concentration of hypertonic saline on efficacy and safety of epidural adhesiolysis. Anesth Analg 2017; 124: 2021-9.

4. Gerdesmeyer L, Wagenpfeil S, Birkenmaier C, Veihelmann A, Hauschild M, Wagner K, et al. Percutaneous epidural lysis of adhesions in chronic lumbar radicular pain: a randomized, double-blind, placebo-controlled trial. Pain Physician 2013; 16: 185-96.

5. Ji GY, Oh CH, Moon B, Choi SH, Shin DA, Yoon YS, et al. Efficacy of percutaneous epidural neuroplasty does not correlate with dural sac cross-sectional area in single level disc disease. Yonsei Med J 2015; 56: 691-7.

6. Moon SH, Lee JI, Cho HS, Shin JW, Koh WU. Factors for predicting favorable outcome of percutaneous epidural adhesiolysis for lumbar disc herniation. Pain Res Manag 2017; 2017: 1494538.

7. Park SH, Ji GY, Cho PG, Shin DA, Yoon YS, Kim KN, et al. Clinical significance of epidurography contrast patterns after adhesiolysis during lumbar percutaneous epidural neuroplasty. Pain Res Manag 2018; 2018: 6268045.

8. Nicholas M, Vlaeyen JWS, Rief W, Barke A, Aziz Q, Benoliel $\mathrm{R}$, et al. The IASP classification of chronic pain for ICD-11: chronic primary pain. Pain 2019; 160: 28-37. 